\title{
Learning games creation: IMIE model
}

\author{
Ali Abarkan, Abderrahim Saaidi, Majid Ben Yakhlef \\ Laboratory of Engineering Sciences, Sidi Mohamed Ben Abdellah University of Fez, Faculty Polydisciplinaire, Taza, \\ Morocco
}

\begin{tabular}{l} 
Article Info \\
\hline Article history: \\
Received Sep 9, 2020 \\
Revised Feb 15, 2021 \\
Accepted Mar 5, 2021 \\
\hline
\end{tabular}

Keywords:

Learning games

Models

Pedagogically

Serious games

Sub-models

\begin{abstract}
In this article, we propose a new model for the learning games design, which aims to enrich and solve the problems of existing models. From the work carried out around the models of educational games, we carefully identify a series of steps to follow, taking into account the simplicity, ease of adaptation and the integration of several factors interest such as the integration of a set sub-models treated pedagogically define the pedagogical side in the game, also the distribution of the intervening necessary for each of the stages to ensure better collaboration between them, for the purpose to helping the creators to trace their path from the start of the creation, in order to achieve the best example of games with an adequate oscillation pedagogical-fun, that will meet the requirements of existing classical teaching methods.
\end{abstract}

This is an open access article under the CC BY-SA license.

\section{Corresponding Author:}

Ali Abarkan

Laboratory of Engineering Sciences

Sidi Mohamed Ben Abdellah University of Fez

Faculty Polydisciplinaire

Taza, Morocco

Email: ali.abarkan@usmba.ac.ma

\section{INTRODUCTION}

In our daily life, humans use games most of the time as a medium for entertainment and leisure. During the last decade, a new attempt called "serious games" has been put in place to take advantage of the use of video game principles and technologies, for applications which are not strictly gaming in nature [1]. This birth of serious games has strongly shown its presence in several fields of application, which requires classification, by several authors, according to the targeted sector (health, defense, and education) [2], [3] and also according to the type of message to be transmitted (educational, informative...) [4], [5]. In this sense, several researchers have decided to discard the term serious game to specify the object of the game [6]-[9]. For example, Marfisi-Schottman [10] proposed the term Learning Game for serious games that are used in a purely educational context, or as part of training at all levels. This classification requires the identification and specification of design models according to the target sector. This will allow creators to meet the needs and standards demanded by each type of serious games (dedicated for each sector) [11].

In this article, we are interested in learning games (LG), that is, games dedicated to the educational sector. Recently, several surveys [4], [5], [12], [13] have shown the great usefulness of serious games in this sector, this attempt at learning games aims to enrich traditional teaching methods to acquire complex skills in higher education. Despite the effectiveness and good reputation of educational games, several factors limit the spread of this tool in the educational system of several universities. This is mainly due to the high cost of the design, and also to the difficulty that designers consider in the absence of clear and easy to adapt tools [14]. The problem is therefore to define models dedicated to the creation of learning games with the following objectives: 
- Guarantee a more adequate level of simplicity and ease of adaptation.

- Allows the teacher to fully play his role in the teaching process based on serious games.

- Distribute tasks for Intervening to ensure better collaboration between them.

In order to meet the objectives defined above, we have found that it is very interesting to propose a model, for the creation of learning games, which takes into account the limitations studied. The main objective of this model is to ensure that designers develop their ideas in a way that is simple, clear and that does not require computer skills to apply it, moreover that the model is applicable for any 'she idea of a game. Each step of this model is presented by its necessary intervening to ensure better collaboration and distribution of tasks. The main actor in education systems (the teacher) is responsible for taking action and defining his own content to be transmitted from the start of the creative process, and to follow it in most stages. In the next, we placed a set of sub-models (S-M) to pedagogically study the content of the game, and to draw the interesting factors (domain, motivation and scenario) to guarantee a better pedagogical-play adaptation in the next stage of the game interpretation.

In the rest of this introduction, we present the related works of some of the most popular models in the field of creating the learning games and serious games in general. The second part is reserved for the description of the proposed model, then we will detail each of the stages constituting our model. A comparative study between the proposed model compared to existing models is presented in the third part.

To respond to the problem of designing serious games and more specifically learning games, several authors have proposed models and methods that are often generic and more rarely have been proposed for a targeted type of game [15]. Paquette et al. [16] proposed an engineering method for interactive learning environment (MISA) which consists of six main phases: Definition of project, preliminary analysis, development of the training architecture, design of the educational material (texts and exercises), development and validation of the educational material and preparation for the implementation of the training. For each phase, they specified documents to prepare. This methodology was born from the great experience of TELUQ University (University of distance education affiliated to the University of QUBEC), for distance training for many years [17]. Despite its robustness and originality, this method has shown its weakness in terms of adaptation, architecture, number of phases and documentation required for each step [18].

Marfisi-Schottman et al. [19] designed an educational method called "case method" dedicated to the creation of learning games. It is based on the problem-based approach that has been used for several years as a teaching method in the Harvard business school [20]. The application of this method is very simple and valid in many areas, because it allows learners to put themselves in front of a problem situation to help them make the right decision. Despite its usefulness and ease of adaptation, this approach is limited because it is valid just for possible problem areas or situations. Mathieu et al. [21] published a new model for the creation of learning games called DISC, which is based on four phases: domain model, interaction, scenario and context of use. The novelty of this model is the integration of the teacher in the process of creating the learning games. The weak part of this model is the use of hierarchies for each stage which makes its application slow and complicated.

Nadolski et al. [22] studied an EMERGO methodology for the creation of learning games of survey type for higher education, this method consists of five phases: Define (analysis and description of the case through a set of questions), scenario (conception of the overall scenario of the game from all sides), development (creation and development of the game), implementation (testing the relevance of the game by the student and the teacher) and evaluation (verification of the validation of the requirements defined initially). The EMERGO methodology remains limited by its adaptation except for the investigation games. This reduces its diffusion in the market for the creation of serious games. Furthermore, the iteration cycle proposed in this model is very slow, this will handicap the users of this model.

McMahon, [23] has defined a model for the creation of serious games called DODDLE inspired by the generic model ADDIE [24]. This model is articulated on four phases: Preliminary analysis (describe, define the methodology and the desirable objectives of the game), general design (creation of the concept and the choice of the type of the game), documentation for the design (present the detailed scenario of the game taking into account interfaces and interactions), and documentation for development (dealing with game mechanisms and variables). Despite its simplicity, this McMahon model remains very generic and proposed for novices in the field of serious game design. Because, this model requires the presence of several factors that the intervention of the teacher, evaluation part, distribution of tasks to the collaborators ..., so that it is in the standards.

The company KTM Advance has treated a model for the design of serious games [25] which is composed of five phases: needs analysis (definition and identification of: educational content, technical and educational characteristics of the game), game design (proposal details of the game: Scenario, game play, interaction, ...), development of the prototype (testing the relevance of the objectives initially targeted by a 
prototype), iterative and final delivery (development of the game according to an iterative process to make requested modifications, in order to reach the final version, verifying the objectives traced from the start). Despite KTM Advance coming from E-learning, we notice the absence of the teacher's touch during the whole creation process. In addition, the structuring of the phases is close to that of the video games.

\section{PROPOSED MODEL}

In this section, we present the general framework of our proposed idea to solve identified problems, in order to detail each of the stages constituting our model.

\subsection{General framework}

Following a study of several models and methodologies for the creation of serious games, we noticed that most of them proposed for a utility in all the sectors of serious games. Furthermore, several surveys [13], [26] have shown the great usefulness of serious games in the field of education compared to other sectors through the two main elements: learning and motivation. Due to this hypothesis, we decided to enrich the existing models with a new dedicated tool specifically to help the creators of learning games to achieve their objectives in a very simple and effective way. Our proposed model is called IMIE (identification, modeling, implementation and evaluation). The objective is to create educational games of any type (investigation, adventure game, ...) in educational standards by planning and analyzing the objectives of a targeted sampling of learners. Then, the novelty of our proposal is the definition of a set of necessary sub-models (S-M) (domain, motivation and scenario) to allow creators to choose their tools to use to achieve the desired objectives. Furthermore, in our proposed idea, we ensured the integration of simplified, clear steps, which do not require a lot of skills to adapt them. As well, to avoid the collaboration problem that can be found in certain models, we have tried to distribute the tasks among the Intervening whose roles are defined below.

\subsubsection{Teacher}

The teacher is the main actor in the process of creating the learning games. He must define, in terms of skills, prerequisites, content and objectives of the various pedagogical activities. Also, he must take into account the context of the game to modify, and possibly adjust the description of the educational content to be transmitted. Similarly, he must collaborate on the one hand, with the pedagogue who masters the existing and conceivable educational functionalities of the game during the formalization of the all S-M. On the other hand, it must collaborate with the creator of the game who is designated for identify the idea of the game adapted to the type of learning desirable to transmit. It also monitors learners to judge the effectiveness of the game and measure its effect on them.

\subsubsection{Pedagogue}

$\mathrm{He}$ is the actor-orchestra of educational and playful modeling. He intervenes throughout the game creation cycle. He is able to discuss, with the teacher and the creator developer of the components, in the proposal idea of the game before applying the S-M proposed by the designer. He may also participate in the use of the S-M in terms of content and pedagogic. Based on the idea defined, he can support the game creator in the implementation stage to ensure an adequate educational and playful adaptation. As well, he can also communicate with the tutor to make modifications in the event of a problem in the game evaluation stage.

\subsubsection{Game creator}

He's the video-game modeling artist. He is involved in the two stages of the game design cycle: identification and implementation. In the identification phase, he can collaborate his game idea with the teacher and the pedagogue to choose either to use already existing game frames or to propose a new idea, whose general objective is compatible with the educational content on the one hand, and with the educational scenario on the other. In the implementation phase, He plays the most dominant role in ensuring better game play scripting, choosing the best playful interfaces adapted with the educational content to allow the learner to navigate the game with very high motivation.

\subsubsection{Learner}

$\mathrm{He}$ is the main beneficiary of learning games. He uses this type of game to acquire new skills, apply concepts acquired in the course, reinforce knowledge, and in addition he can repeat a game session several times to better adapt the most complicated parts of the course. From a more technical point of view, he wishes that the learning game should be a mobile support and downloadable on different operating systems to offer him the possibility of playing with any device (computers and smart -phones) and at any time. He also 
wants to be provided the adequate tools with high motivation. In Table 1, we have presented the intervention parts for each actor during the game creation cycle based on our IMIE model.

Table 1. Intervention of the actors in the creation of a game at base of our IMIE model

\begin{tabular}{ccccc}
\hline Intervening & Identification & Modeling & Implementation & Evaluation \\
\hline Teacher & $\mathrm{X}$ & $\mathrm{X}$ & - & $\mathrm{X}$ \\
Pedagogue & $\mathrm{X}$ & $\mathrm{X}$ & $\mathrm{X}$ & - \\
Game creator & $\mathrm{X}$ & $\mathrm{X}$ & - & - \\
Learner & - & - & - & $\mathrm{X}$ \\
\hline
\end{tabular}

In order to detail the role of each actor involved in our model, Figure 1 presents the general architecture of our proposed IMIE model for the creation of learning games. We have expressed each phase according to his role, the Intervening, also the transition, composition and iteration links connect the stages together.

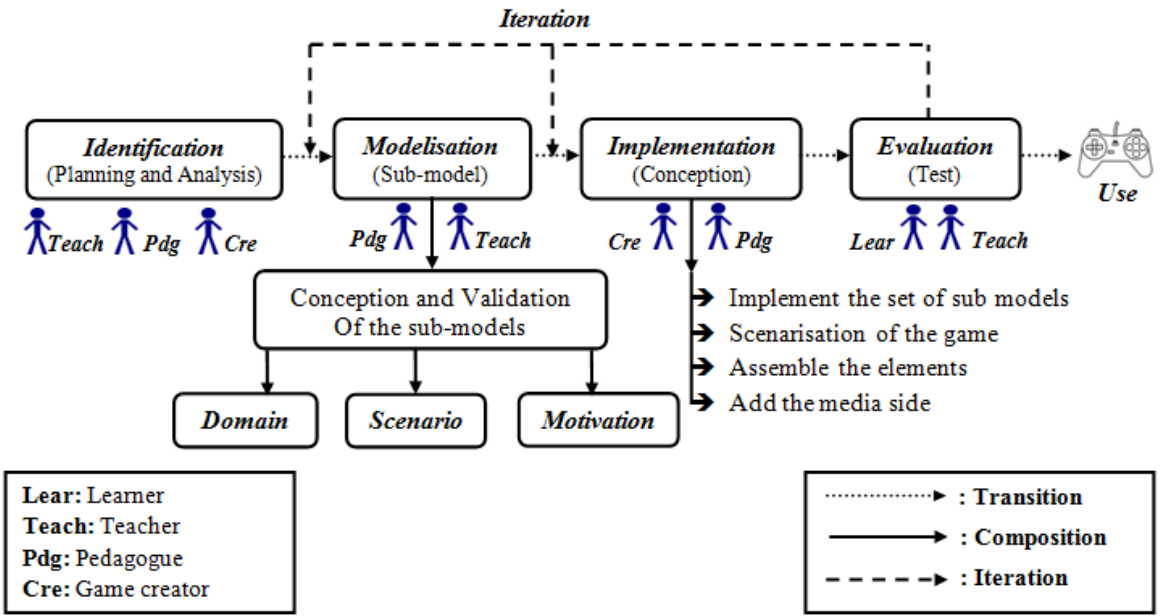

Figure 1. IMIE model for Learning Games creation in educational standards

\subsection{Phases of IMIE model}

This part is devoted to explain the four phases constituting our proposed model. We will detail the role of each step in the process of creating a learning game by IMIE.

\subsubsection{Identification}

In the serious game creation cycle, identifying the game idea is the first step in most creation models, in which each designer must define all of the desirable goals. For our model, identification is based on two main functions: Planning and analysis. Firstly, the planning phase is reserved to define the desirable objective through which the idea of the game must be expressed, the strong point of our model for this stage is the identification of the collaborators necessary to intervene. The teacher in collaboration with the pedagogue and game creator must discuss successively the educational content (the learning objectives, the educational objectives and the necessary prerequisites) to be transmitted, the context of the game and the educational tools to be used. On the other hand, the collaborators need to analyze the characteristics of the targeted learners (the strong and weak points), the environment in which this game should be used, and also its usefulness in the education system.

\subsubsection{Modeling}

This phase consists of shaping the learning system, the pedagogue in collaboration with the teacher applying the set of sub-models to the proposed content, to derive the domain, motivation and scenario factors, including the objectives is to ensure better pedagogical-play collaboration in the following phase. The Figure 2 explains the constituent elements of the set of sub-models that we have proposed to study the chosen educational content. 


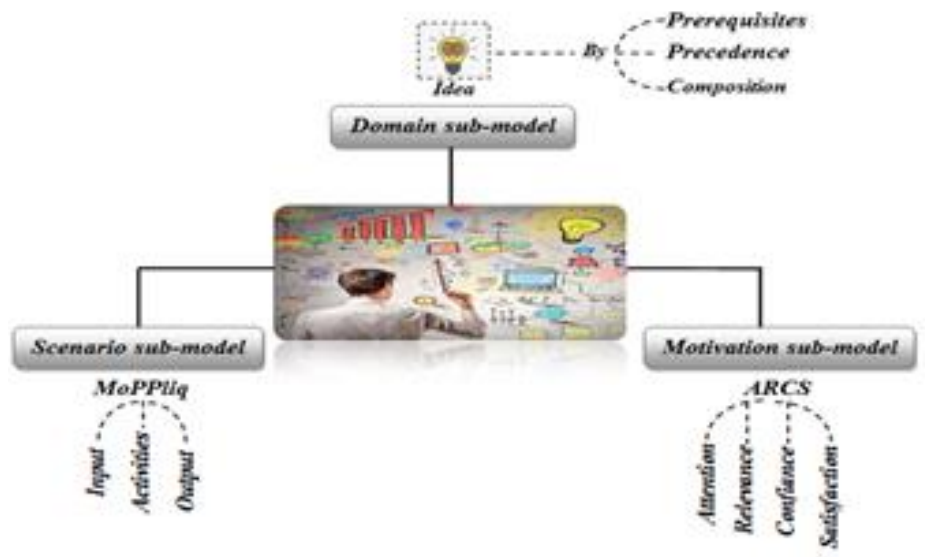

Figure 2. Sub-models concerning the IMIE model

a. Domain sub-model

This is the element that presents the idea of the game in a detailed and structured way [28]. The teacher must present the content to be transmitted through the game with ideas and skills in the form of a graph. The latter is made up of prerequisites to be used to acquire new skills. Furthermore, the representation of the domain sub-model is based on pre-requisite and composition links which link skills together. The main objective is to describe the proposed idea, in terms of skills linked to each other, and to use this model in the 3rd step of our model (implementation).

b. Motivation sub-model

In the field of creating serious games, we have noticed in most models that the majority of designers have overlooked the importance of motivators in their creation processes. This factor is the most important element that makes the difference between serious games and other types of distance learning. From there, we insisted on its presence in the S-M of our model, to help creators trace their motivational path from the start, in order to create in learners a kind of very interesting motivation. To integrate the motivation factor, we studied several models such as: Maslow [28], Bandura [29], Deci and Ryan [30], Keller [31]. The difference between these authors is the vision by which they defined this motivation model. In our case, we found on the Keller model (ARCS model) which is characterized by its clarity, ease of integration and adaptation. In addition, this model, which depends on four very interesting factors defines the motivational state in a global manner and in all aspects. In Table 2, we also presented the role of each factor of the ARCS motivation model.

Table 2. Elements of the ARCS motivation sub-model

\begin{tabular}{cc}
\hline Factors & Role \\
\hline Attention & Encourage the learner to broaden his knowledge by providing an initial stimulus \\
Relevance & Connect with the learner by making connections between various past, present and future activities \\
Confidence & Encourage the learner to reflect on recent experience \\
Satisfaction & Let the learner use the newly acquired knowledge whenever necessary. \\
\hline
\end{tabular}

\section{c. Scenario sub-model}

Following the definition of the domain and motivation model, the last element in all of the submodels is to script the idea of the game. In the literature for scripting a serious game, there are several models and tools: WEEV [32], ScenLRPG [33], Legadee [10]. Through the study of several tools dedicated to this task, we aimed to integrate the MoPPliq model [34] as a tool that will help creators to trace their course in the form of pathways that allow them to represent their pedagogical aspects and even the playful aspect. The strong point of this tool is the possibility of presenting several scenario architectures (linear, non-linear, ...) in a simple, understandable and usable way even for non-professionals (teachers).

\subsubsection{Implementation}

This is the third step of our model which is reserved squarely for the design of the elements constituting the game. Following the interpretation of the sub-models proposed in the previous step, the pedagogue must present all the sub-models to the creator of the game. The latter must study its elements to find the components and the media scenario necessary and most suited to the educational context proposed. 
In this stage, the two collaborators (the game creator and the teacher) must work in parallel to design a tool that combines the two pedagogical and playful aspects in an adequate manner. Most of the work during this stage depends on the game creator. The latter intervenes to assemble and implement the fun elements through two possible situations: the first is to propose a new scenario adapted with the pedagogical objectives outlined. The second possibility is to use a framework game that is to exploit the scenario and the interfaces of a game of origin playful after having integrated the pedagogical content in parallel. Except that the second proposal must influence the motivation of learners/players who have already used this scenario with video games. This is why the presence of the pedagogue is necessary to find the best solutions that will help to realize a game with a very interesting motivation for achieve the objectives traced.

\subsubsection{Evaluation}

During the use of the created game, this phase involves evaluating the game in order to post a judgment on its quality and effectiveness. The teacher must test the game on a sample of learners to predict its use in different learning situations, in order to cite the possible improvements to be made to the game, either at the level of the educational aspect defined at the start through the consideration: the choice of content, the distribution of levels,... (Iteration to the all sub-models proposed in the modeling phase by a teacher-pedagogue intervention), or at the level of the playful side resulting from video games, while the game creator is requested to improve the all media elements to ensure a higher motivation rate (iteration to the implementation phase).

\section{DISCUSSION}

To validate the idea of our IMIE model, we have designed to do a comparative study between our approach and a set of the most relevant and referenced models in the field of serious games creation and learning games. The set of models chosen for this study consists of: the MISA model [16] which is among the first engineering methods for a learning system, and which is considered to be a reference approach for most of the methods and models for creating serious games. The EMERGO methodology [22] which is more used in the development of serious games for higher education. Finally, the new DISC model [21] which is dedicated specifically for the design of learning games. The framework for our discussion revolves around four points that are most interesting for each model designed for creating learning games. The first point is the definition of the necessary documentations that define each model. The second is the intervention of the main actor of education systems (the teacher) and his role throughout the creation process. The third point is the distribution of the necessary intervening for each of the stages. The fourth point is the iteration possibility offered by each model, which offers us the possibility of reengineering in case of not meeting the needs expected by the game created. The Table 3 summarizes the comparative study carried out according to the four points presented above, and which are the most critical in the process of creating learning games.

Table 3. Comparative study of the IMIE model with the models from the above literature

\begin{tabular}{ccccc}
\hline Model & Documentations & Teacher role & Distribution of intervening & Iteration cycle \\
\hline MISA & Documents & - & - & - \\
DISC & - & In most stages & Intervention: Teacher/Pedagogue & Interesting \\
EMERGO & Questionnaire & - & - & Very long \\
IMIE & Set of sub-models & In most stages & Intervener required for each step & Interesting \\
\hline
\end{tabular}

The first criterion of our comparison is the study of the necessary documentation proposed to apply each of his models (MISA, DISC and EMERGO). For example, Paquette et al. [16] of the MISA model have specified documentation to prepare (graphs, tables, diagrams or texts) for each activity, which influences the adaptation of this model. On the other hand, the authors of the EMERGO model [22] chose to work on questionnaires to take into consideration the opinions of consumers and users. The assembly of opinions and statistical calculations take considerable processing time, which will also negatively influence the duration of the model application. For our IMIE model, we took into consideration the interest of this point, and his absence in the majority of the design models of the domain (DISC model), this pushed us to integrate the all sub-models (of domain, motivation and scenario) treated pedagogically. The sub-models are very powerful for the creation process, their interest is to allow the creators to trace their paths to follow from the start of the process before his implementation in the design phase.

The second criterion that we have taken into consideration in this comparative study is the integration of the teacher in the creative process taking into account his important role of reacting in most phases of design. For example, if we talk about the MISA model, we notice the complete absence of teacher 
intervention in the entire process, so the use of this model to create an learning game remains very complicated because, of these various features in the field, starting with the definition of the content to be transmitted until the sampling precision of the learners/players targeted. The same for the EMERGO model, the authors thought of dedicating this model to the creation of learning games, but they did not integrate the main actor of the education system (the teacher). On the other hand, in the DISC model, the authors took into account the teacher's interest in the creation process through his presence almost in all the stages, due to his weight and his importance by his major responsibility, for integrate play into the education system. For our IMIE model, we designed to present the teacher in the different situations from the start, and almost in all stages. Furthermore, we have specified his intervention in each of the stages according to his responsibilities (See paragraph 2.1.1).

The 3rd criterion focuses on the distribution of intervening during the creation process. It facilitates collaboration during the creation process. Furthermore, it makes it possible to identify the tasks to be performed by each intervening in order to avoid the problem of confusion that causes creators during the creation process. For example, the authors of the MISA and EMERGO models neglected the importance of this criterion, which is noticed during their creation process, which will create problems during the distribution of tasks. Similarly, the authors of the DISC model have taken this point into account, which directly influences the creation cycle of this model, the only remark is that the authors have neglected, respectively, the importance of setting up the creator of the game, and the integration of the main beneficiary of educational games. For the case of our IMIE model, we have overcome the problems linked to the models mentioned above (MISA, EMERGO and DISC) by integrating the necessary intervening (learner, teacher, pedagogue and creator of the game) in each step, in order to ensure better collaboration between them, and accelerate the pace of game creation.

The final criterion of our discussion is the presentation of the iteration cycle in the process of creating a serious game. The benefit of this iteration cycle is that it gives creators the flexibility to adjust and modify in-game content if they are not satisfied, until a more efficient and better version of the game is achieved. We notice that this iteration possibility is totally absent in the MISA model, this limits its use by some creators. On the other hand, the authors of the DISC and EMERGO models took this criterion into consideration. For example, in the DISC model the iteration cycle is well presented, it allows the creators, each time, to go back to the previous phase to make changes. For EMERGO, the authors took into account to integrate the possibility of iteration in their courses. Despite the advantage of this option, they proposed a very long cycle (iteration towards the first step of the process), this will create problems for users of this model. For the case of our proposed model, we presented the iteration cycle in a way that is very suitable for our objectives. If they are not satisfactory, the creators have the option of either returning to the modeling stage to verify the effectiveness of the defined Sub-Models, or to the implementation stage to reconsider the media aspect of the game, until to have obtained the desired game version.

\section{CONCLUSION AND PERSPECTIVES}

To help the creators of educational games, we have presented in this work, a new model called IMIE dedicated mainly to the creation of this type of games. The novelty in this work is the integration of the submodels which will allow us to pedagogically treat the chosen content, to draw the domain, motivation and scenario factors, in order to assemble them with the media elements in the phase of implementation. Likewise, we took into consideration the integration of the intervening necessary for each of the phases, starting with the teacher who is considered to be a main actor in this type of educational games. This aims to increase the rate of use the serious games in the education system, as part of the renewal of classical teaching methods.

In order to apply the IMIE model proposed in this article, we will consider using it for the creation of a learning games. The general idea is based on the creation of a game for learning a programming language, the objective of which is to enrich the classic teaching aids: Courses, tutorials and practical work, by a new tool which is characterized by his interesting motivational side. The setting of the game should be chosen on the basis of a questionnaire asked of the targeted learners to meet their needs. The educational content must be selected by the teacher according to the difficulties that cause the learners during the educational operation of learning this programming language, to ensure better educational-fun adaptability.

REFERENCES

[1] S. Natkin, "Jeux vidéo et médias du XXIe siècle," Vuibert, p. 112, 2004.

[2] M. Zyda, "From visual Simulation to Virtual Reality to Games," IEEE Computer, vol. 38, no. 9, pp. 25-32, Sept. 2005, doi: 10.1109/MC.2005.297. 
[3] D. R. Chen and S. L. Chen, "Serious Games:Games that educate, train and inform," Boston: Thomson Course Technology, 2005.

[4] L. Michaud and A. Julien, "Serious Games: Advergaming, edugaming, training," IDATE Consulting and Research, 2008.

[5] D. Djaouti, J. Alvarez, and Jean-Pierre Jessel, "Classifying Serious Games: The G/P/S Model," In Handbook of Research on Improving Learning and Motivation through Educational Games: Multidisciplinary Approaches, pp. 118-136, 2011, doi: 10.4018/978-1-60960-495-0.ch006.

[6] M. P. J. Habgood, "Zombie Division: Evaluating principles of intrinsic integration," Serious Games Summit, USA, pp. 45-48, 2007.

[7] S. Natkin and J. Dupire, "Entertainment Computing-ICEC 2009," International Conference on Entertainment Computing, 2009,pp. E1-E1, Springer, Berlin, Heidelberg, doi: 10.1007/978-3-642-04052-8.

[8] C. Marias, "Des ressorts de jeu pour une assistance à la conception de scénarios Learning Role-Playing Games," Rencontre Jeune Chercheur-d'Environnements Informatiques pour l'Apprentissage Humain, Lyon, France, 2010.

[9] N. Szilas and W. D. Sutter, "Mieux comprendre la notion d'intégration entre l'apprentissage et jeu," In Actes de l'atelier de la 4ème conférence francophone sur les environnements informatiques pour l'Apprentissage humain, 2009, pp. 27-40.

[10] I. Marfisi-Schottman, "Méthodologie, modèles et outils pour la conception de Learning Games," PhD thesis, 2012.

[11] A. Abarkan, A. Saaidi, and M. B. Yakhlef, "Adapted model for creating the learning games of the java language," 2019 International Conference on Intelligent Systems and Advanced Computing Sciences (ISACS), 2019, pp. 1-5, doi: 10.1109/ISACS48493.2019.9068893.

[12] L. Segondy, "Rapport Serious games et entreprise: Définition, gestion et marché," Master Redacteur Professionnel, 2013.

[13] L. Michaud, J. Alvarez, V. Alvarez, and D. Djaouti, "Serious Games: Enjeux, offre et marché," EnseignementFormation-Santé-Information \& Communication-Défense, IDATE, 2012.

[14] M. Mathieu, T. Patrice, J. Jean-Pierre, and V. Fabienne, "Towards a Serious Game to Help Students Learn Computer Programming," International Journal of Computer Games Technology, vol. 2009, 2009, doi: 10.1155/2009/470590.

[15] V. Mathieu, M. Nadine, L. Jean-Marc, and G. Gaëlle, "Vers une approche Meta-Design des Learning Games avec le modèle DISC: de la conception à l'analyse des traces d'usage des étudiants par les enseignants," Sciences et Technologies de l'Information et de la Communication pour l'Éducation et la Formation, vol. 25, no. 1, pp. 65-92, 2018, doi: 10.23709/sticef.25.1.7.

[16] G. Paquette, F. Crevier, C. Aubin, J. Rocheleau, C. Paquin, and M. Léonard, "Méthode d'ingénierie d'un système d'apprentissage," Revue Informations In Cognito, vol. 8, 1997.

[17] G. Paquette, D. T. Ileana, L-C. Karin, L. Michel, and D. Ruelland, "La modélisation cognitive, un outil de conception des processus et des méthodes d'un campus virtuel," Revue de l'éducation à distance, vol. 17, no. 3, pp. 4-25. 2002.

[18] G. Paquette, "Le partenariat de recherche université/entreprise," Distances et savoirs, vol. 1, no. 2, pp. 277-288, 2003.

[19] I. Marfisi-Schottman, L. Jean-Marc, and C. Thibault, "Approche basée sur la méthode pédagogique des cas pour créer des Learning Games pertinents dans de nombreux domaines d'enseignement," Actes de la Conférence Environnements Informatiques pour l'Apprentissage Humain, EIAH'2013, May 2013, pp. 67-78.

[20] M. P. McNair and A. C. Hersum, "The Case Method at the Harvard Business School: Papers by present and past members of the faculty and staff," McGraw Hill, 1954.

[21] V. Mathieu, G. Gaëlle, M. Nadine, and L. Jean-Marc, "L'enseignant au cour de la conception de learning games: le modèle DISC," Bème Conférence Environnements Informatiques pour l'Apprentissage Humain, 2017.

[22] R. J. Nadolski et al., "EMERGO: A methodology and toolkit for developing serious games in higher education," Simulation and Gaming, vol. 39, no. 3, pp. 338-352, January 2007, doi: 10.1177/1046878108319278.

[23] M. McMahon, "Using the DODDEL model to teach serious game design to novice designers," Proceedings of Ascilite, pp. 646-653, 2009, doi: 10.1.1.412.919\&rep=rep1\&type=pdf.

[24] M. Molenda, "In Search of the Elusive ADDIE Model," Performance Improvement, vol. 42, no. 5, pp. 34-36, 2003, doi: 10.1002/pfi.4930420508.

[25] V. L. Boudier and Y. Dambach, "Serious game: Révolution pédagogique," Paris, Lavoisier, Hermès science Publications, Interfaces numériques, vol. 1, no. 1, pp. 205-208, 2012.

[26] O. Philippe and A. Julian, "Le Serious game: contexte économique, contexte stratégique et contexte d'actions," Association Observatoire des Territoires Numériques (OTeN), May 2011.

[27] El-Kechaï Naïma, J. Malero and J. M. Labat, "Quelques enseignements tirés de l'application de la Competencebased Knowledge Space Theory aux Serious Games," IC2015, Jul 2015, Rennes, France. collection AFIA, 2015.

[28] P. L. Maslow, "Herzberg et les théories du contenu motivationnel," Centre Lillois d'Analyse et de Recherche sur l'Evolution des Entreprises UPRESA CNRS 8020, 2002.

[29] A. Banduraë, "la théorie sociale-cognitive des buts," revue québécoise de psychologie, vol. 14, no. 2, 1993.

[30] L. E. Deci and R. M. Ryan, "Favoriser la motivation optimale et la santé mentale dans les divers milieux de vie," Canadian Psychology/Psychologie canadienne, vol. 49, no. 1, pp. 24-34, 2008, doi: 10.1037/0708-5591.49.1.24.

[31] J. M. Keller, "Development and use of the ARCS model of instructional design," Journal of instructional development, vol. 10, no. 3, pp. 2-10, 1987, doi: 10.1007/BF02905780.

[32] E. J. Marchiori et al., "A narrative metaphor to facilitate educational game authoring," vol. 58, no. 1, pp. 590-599, 2012, doi: 10.1016/j.compedu.2011.09.017.

[33] C. Mariais, "Modèles pour la conception de Learning Role-Playing Games en formation professionnelle," Médecine humaine et pathologie, Université de Grenoble PhD thesis, 2012.

[34] M. Bertrand, C. Thibault, and L. Jean-Marc, "Modélisation des parcours pédago-ludiques pour l'adaptation des jeux sérieux," Gème Conférence sur les Environnements Informatiques pourl'Apprentissage Humain, IRIT Press, 2013, pp. 55-66. 